\title{
Unusual rearrangement of dihalocyclopropanes
}

\author{
Christopher K. Jankowski ${ }^{\mathrm{a}, *}$, Antoun Bou Laouz ${ }^{\mathrm{a}}$, Denis Lesage ${ }^{\mathrm{a}}$ and Eduardo Diaz T. ${ }^{\mathrm{b}}$ \\ ${ }^{a}$ Département de chimie et biochimie, Université de Moncton, Moncton, NB E1A 3E9, Canada \\ ${ }^{\mathrm{b}}$ Instituto de Quimica, UNAM, Cd Universitaria, Del. Coyoacan, Circuito Exterior, 04510 Mexico, \\ D.F., Mexico
}

\begin{abstract}
Dihalocyclopropanation of the double bond of some olefins, leading to dihalocyclopropanes, offered an opportunity to perform their rearrangement to dihalomethylvinyl with Hiyama type reagents, in presence of cationic system such as $\mathrm{Cr}^{2+} / \mathrm{Cr}^{3+}$. The chain elongation of alkenes via the gem-dihalocyclopropanes produced $\alpha, \beta$-unsaturated aldehydes and acids.
\end{abstract}

\section{Introduction}

Dihalocyclopropanes are interesting starting materials to attempt some rearrangements. When attached to cyclic structures with an endocyclic-double-bond, the extension of the cycle takes place, usually with help of the phase transfer catalyst [1,2]. Conversely, the formation of allene is expected for some exocyclic double bond originated dihalocyclopropanes [3]. We recently have reported on Eliel's-reagentsinduced reactions of dihalocyclopropane lactones, and demonstrated the formation of allenic derivatives (dihalo, monohalo and fully reduced) from exocyclic methylenes [4,5] with Hiyama reagents in situ formed $\left(\mathrm{Cr}^{+2} / \mathrm{Cr}^{+3} \mathrm{H}^{-}\right.$, DMF) [6].

This family of Lewis acid reagents, consisting of a pair of cations, is necessary to perform this rearrangement. During this reaction, the reduction of dihaloallene takes place because of both the formation in situ of $\mathrm{Cr}^{+2}$ cation and presence of the hydride ion.

We studied the behavior of the endocyclic double bond with the dihalocyclopropanes attached to a cyclic structure. When reacted with Hiyama reagent, new rearrangement products were observed with low yield. The structure, of these products displayed the dihalomethylvinyl moiety (Scheme 1).

This functional group is a potential precursor of $\alpha, \beta$-unsaturated aldehydes or acids. Faced with what is a potentially new rearrangement, it was necessary to compare it to similar reactions involving either carbene addition, Lewis-acid-induced rearrangement, synthesis of $\alpha, \beta$-unsaturated carbonyl compounds and, the Hiyama reaction. Closely related reactions included Reimer-Teimann, DoeringLaflamme, Ciamician-Dennstedt, retro-Griffin and Hiyama-Heatchock reactions, most of which are<smiles>O=CC1=CCCCC1</smiles>

Scheme 1. General rearrangement scheme.

*Corresponding author. Département de chimie et biochimie, Université de Moncton, Moncton, NB E1A 3E9, Canada. Tel.: +1 506858 4331; Fax: +1 506858 4541; E-mail: jankowc@umoncton.ca. 
<smiles>C1=CCCCC1</smiles><smiles>C1=COCCC1</smiles>

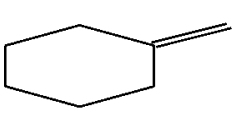

3<smiles>CC1CCC2CC1CCC2C</smiles><smiles>C=CCCC(C(C)C)[C@H]1CC=C(C)[C@H]1C(C)C</smiles>

5

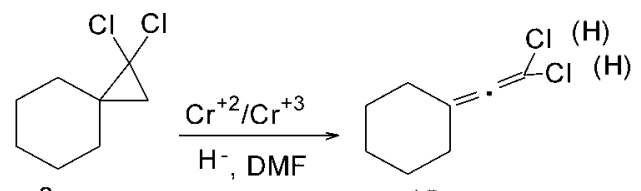

$\underline{8}$

15

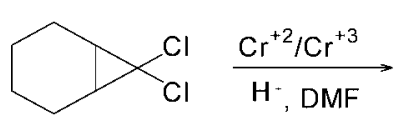

$\underline{6}$<smiles>O=C(O)C1=CCCC(C2=CCCCC2)C1</smiles><smiles>ClCC1CCCCC1</smiles><smiles>CC1=CCCCC1</smiles>

11

$1 \underline{3}$ 14<smiles>ClC1(Cl)C2CCCOC21</smiles><smiles>CC1CCC=COC1</smiles>

22 $\mathrm{CHCl}_{2}+$<smiles>[OH+]CC1CCCCO1</smiles>

23<smiles>[ClH+]CC1CCCCO1</smiles>

24

Scheme 3. Rearrangement products of dihalocyclopropane.

performed on the aromatic compounds [7-11]. Finally, from a mechanistic standpoint, the obtention of dihalomethylvinyl from dihalocyclopropane should follow one electron mechanism rearrangement pathway suggested by Wang [12].

We examined over twenty dihalocyclopropanes of which only three cyclohexene (1) and dihydropyrane (2) both of which are endocyclic, as well as limonene (4), which is not only endocyclic, but has a second exo double bond on a terminal methylene, react along the new dihalocyclopropane-dihalomethylvinyl direction with a reasonable yield (Scheme 2).

Subsequently, some other Lewis acids able to produce two neighboring oxidation states such as $\mathrm{Ce}^{+3}$ or $\mathrm{Sm}^{+2}$ as well as with $\mathrm{Cr}^{+3}$ alone (without hydride), were applied to $\underline{6}, \underline{7}, \underline{8}$ and $\underline{16}$ dichlorocyclopropane adduct rearrangement. The post-reaction mixtures were examined using NMR and GC-MS. The most interesting results were obtained for both $\mathrm{Cr}^{+2}$ experiments (Scheme 3).

\section{Results and discussion}

First, the dihalocyclopropane derivatives were prepared by phase transfer catalysis. The olefins $\underline{1}, \underline{2}$ and $\underline{3}$ gave dihalocyclopropanation in the range of $85-90 \%$ when tributyl-ammonium chloride (TEBA) 
(a)

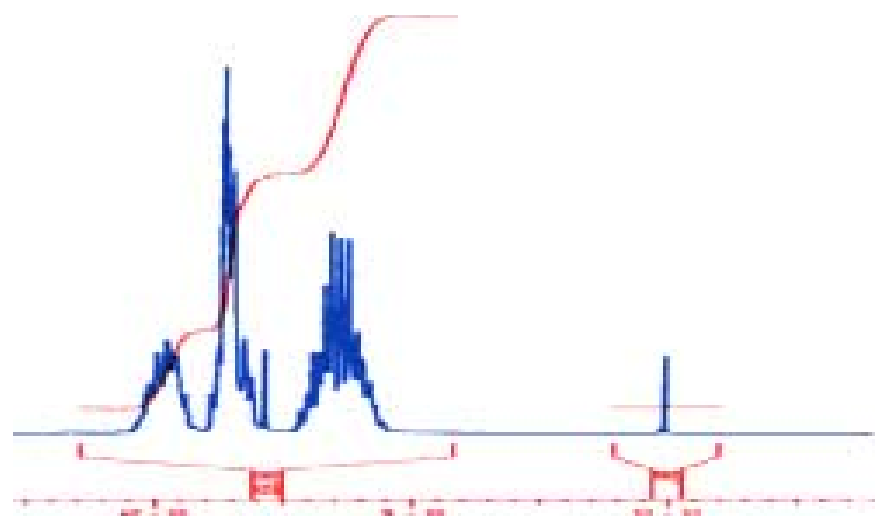

(b)

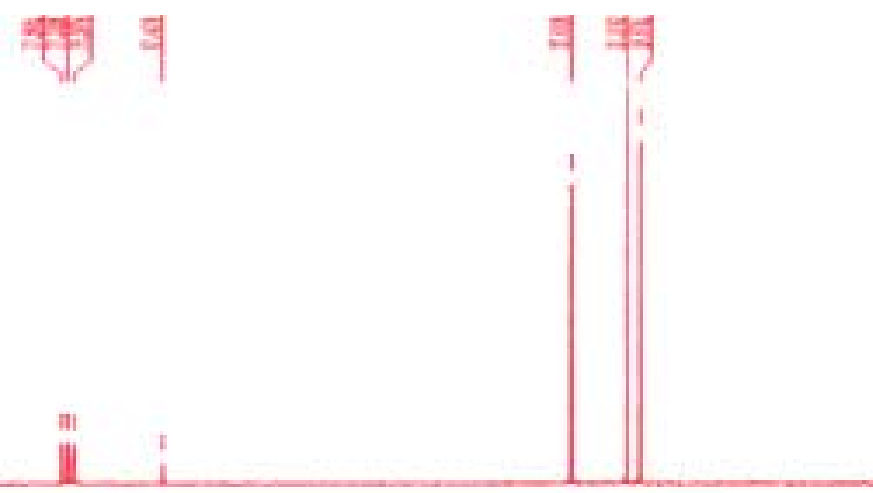

Fig. 1. (a) H-1 NMR spectrum of $\underline{6}$. (b) C-13 NMR spectrum of $\underline{6}$

catalyst was applied according to Makosza's procedure [1]. The proton NMR (200 MHz) showed characteristic of cyclopropane proton signals at $2.06 \mathrm{ppm}$ for 7,7-dichloronorcarane () (Fig. 1a), $1.42 \mathrm{ppm}$ and $3.22 \mathrm{ppm}$ for 7,7-dichloro-oxonorcarane (7) (Fig. 2a) and $1.17 \mathrm{ppm}$ for 1,1-dichlorospiro[2.5]octane () (Fig. 3a); the spectrum C-13 for corresponding cyclopropane moiety had signals at $20.2 \mathrm{ppm}$ for $\underline{6}$ (Fig. 1b) and 24.5 and 59.0 for $\underline{7}$ (Fig. 2b), and 25.1 and 67.5 ppm for $\underline{8}$ (Fig. 3b). When $\underline{6}$ is subjected to Hiyama reagent formed in situ the corresponding aldehyde $\underline{10}$ (2-cyclohexenal), the acid 11 (1cyclohexene carboxylic acid), the reduced starting material 1-methylcyclohexene (14) and the dichlorosubstituted rearrangement product dichloromethylencyclohexene (9), were obtained with a respective yield of $8,12,6,14 \%$ (total transformation of $\underline{6}$ yield $40 \%$ ). In the case of the commercial $\mathrm{Cr}^{+2}$ (Aldrich Chemicals, $\mathrm{CrCl}_{2}$ ) neither aldehyde $\underline{10}$ nor monochlorosubstituted product $\underline{13}$ was observed, and the acid $\underline{11}$ and the totally reduced compound $\underline{14}$ were obtained with yield of only $4 \%$ and $6 \%$, respectively (10\% of total yield transformation).

In the presence of $\mathrm{Cr}^{+3}$ (Aldrich Chemicals, $\mathrm{CrCl}_{3}$ ) none of the rearrangement products were observed (Table 1).

For dihalocyclopropane fixed on the dihydropyrane (2) the in situ produced $\mathrm{Cr}^{+2}$ reagent only lead to the formation of 2-(dichloromethyl)-3,4-dihydro- $2 \mathrm{H}$-pyran (22), ${ }^{1}$ 3,4-dihydro- $\mathrm{H}$-pyran-2-

\footnotetext{
${ }^{1}$ The position of the radical could be reversed.
} 
(a)

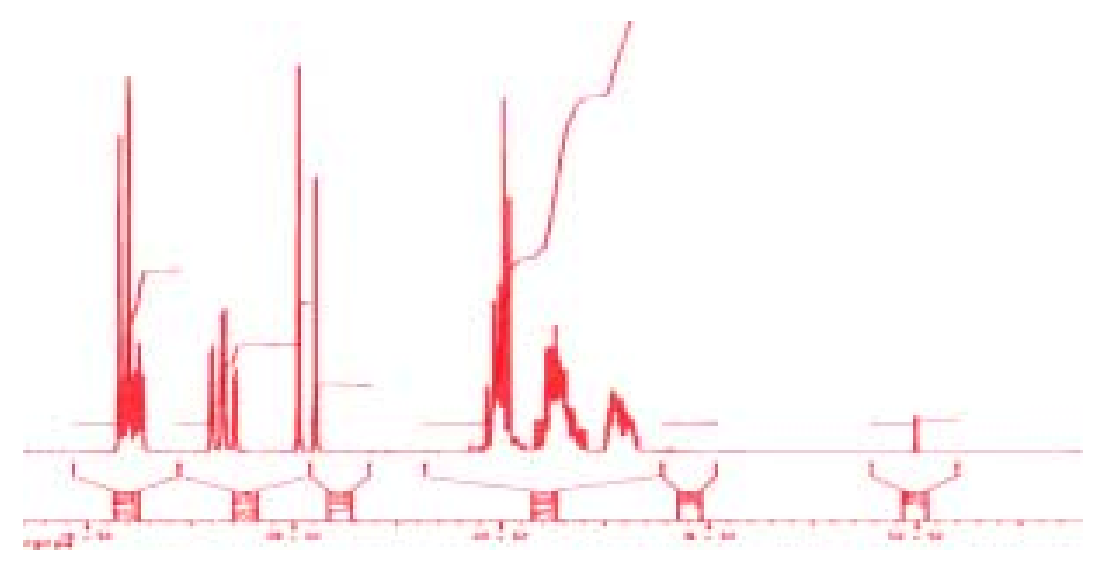

(b)

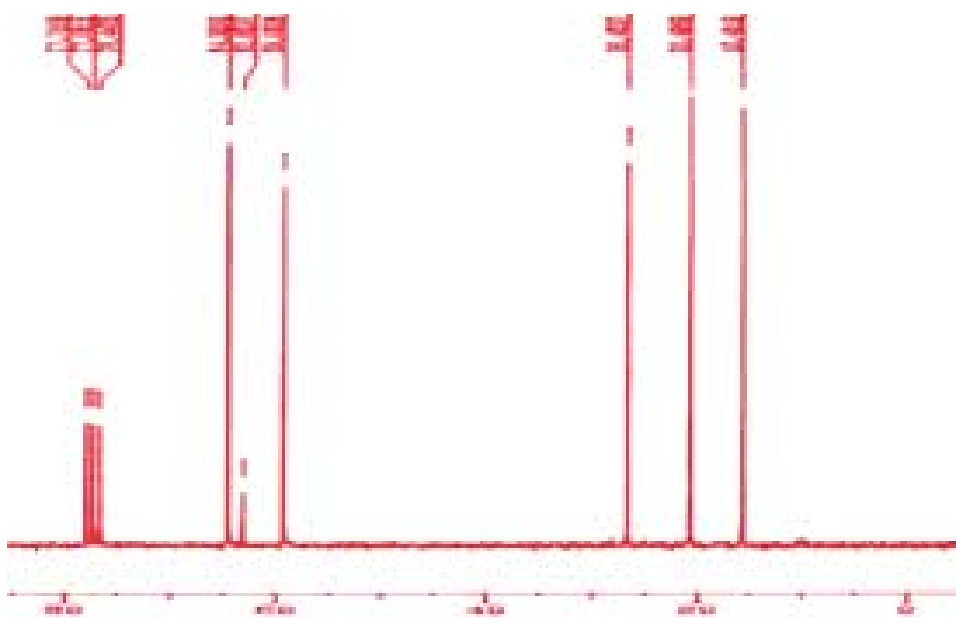

Fig. 2. (a) H-1 NMR spectrum of $\underline{7}$. (b) C-13 NMR spectrum of $\underline{7}$.

Table 1

Efficiencies of dihalocyclopropanes rearrangement of $\underline{6}^{*}$

\begin{tabular}{|c|c|c|c|c|c|}
\hline \multirow[t]{3}{*}{ Condition } & \multirow{3}{*}{$\begin{array}{c}\text { Total } \\
\text { transformation } \\
(\%)\end{array}$} & \multicolumn{4}{|c|}{ Products } \\
\hline & & Totally reduced & Aldehyde & Acid & Dichloromethylvinyl \\
\hline & & $\underline{14}$ & $\underline{10}$ & $\underline{11}$ & $\underline{9}$ \\
\hline $\mathrm{Cr}^{+2}$ in situ & 40 & 15 & 20 & 30 & 35 \\
\hline $\mathrm{Cr}^{+2}$ commercial & 10 & 60 & - & 40 & - \\
\hline
\end{tabular}

${ }^{*}$ Efficiency is reported on the basis of dihalocyclopropane derivative consumed.

carbaldehyde (23) and 2-(chloromethyl)-3,4-dihydro- $2 H$-pyran (24), the dichloromethylvinyle $\underline{22}$, the aldehyde 23 , and monochloro-substituted 24 products, with respective yield of $5 \%, 4 \%$ and $1 \%$ (the total yield is $10 \%$ ). The commercial $\mathrm{Cr}^{+2}$, however, produced only the dichloromethylvinyle 22 compound with a yield of $3 \%$ (Table 2). In neither reaction were seven-membered Makosza products obtained. The acid 25 was not observed in both series of experiments.

When the model exocyclic olefin methylenecyclohexane (3) was transformed into its dihalocyclopropane ( $\underline{8}$ ), and this derivative was tested with Hiyama reagent via similar reaction $9 \%$ of rearranged 
(a)
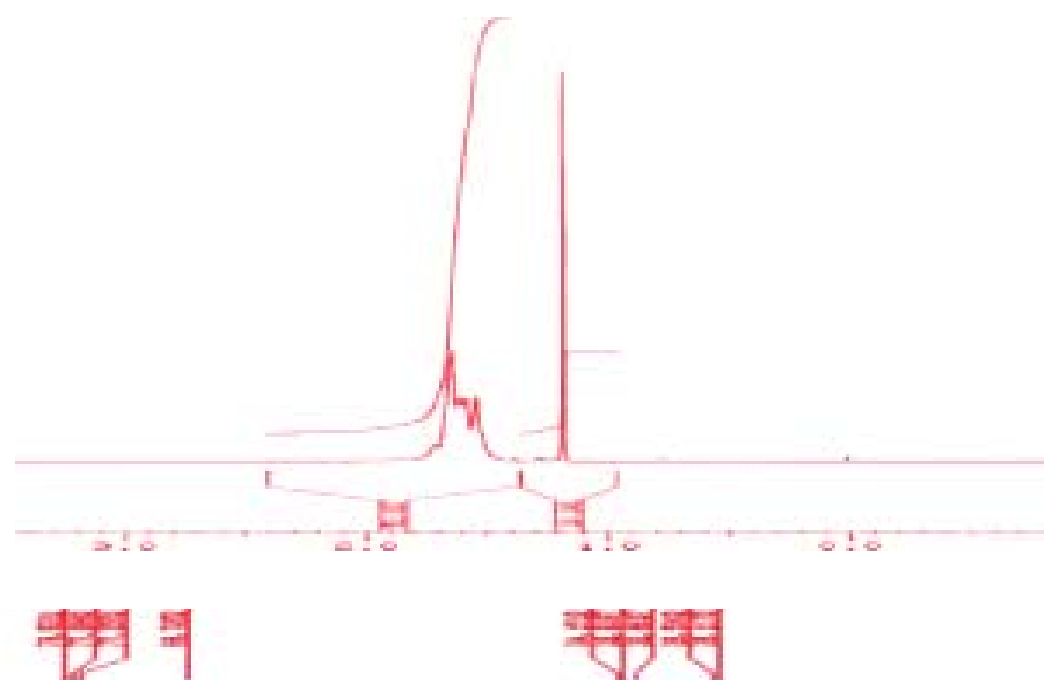

(b)

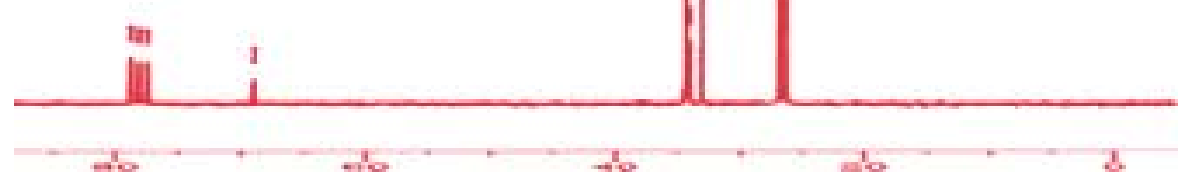

Fig. 3. (a) H-1 NMR spectrum of $\underline{8}$. (b) C-13 NMR spectrum of $\underline{8}$.

Table 2

Efficiencies of dihalocyclopropanes rearrangement of $\underline{Z}^{*}$

\begin{tabular}{lcccc}
\hline Condition & Total & \multicolumn{3}{c}{ Products } \\
\cline { 3 - 5 } & transformation & Dichloromethylvinyle & Aldehyde & Monochloro \\
& $(\%)$ & $\underline{22}$ & $\underline{23}$ & $\underline{24}$ \\
\hline $\mathrm{Cr}^{+2}$ in situ & 10 & 50 & 40 & 10 \\
$\mathrm{Cr}^{+2}$ commercial & 3 & 100 & - & - \\
\hline
\end{tabular}

${ }^{*}$ Efficiency is reported on the basis of dihalocyclopropane derivative consumed.

allenic product (dichloroethenylidene)cyclohexane (15) was obtained (35\% of total yield).

This confirms, that the formation of allene from the spiro dihalocyclopropane takes place, and the rearrangement does not stop on the dihalomethylvinyle step.

The dihalocyclopropanation of limonene ( $\underline{4})$ gives three different derivatives, separated by column chromatography $\left(\mathrm{Al}_{2} \mathrm{O}_{3}\right.$, basic), resulting from the addition of cyclopropane moieties to, either one of the two (endocyclic or terminal methylene) or to both double bonds. The NMR spectrum of the tetrachloro derivative of limonene 7,7-dichloro-4-(2,2-dichloro-1-methylcyclopropyl)-1- 


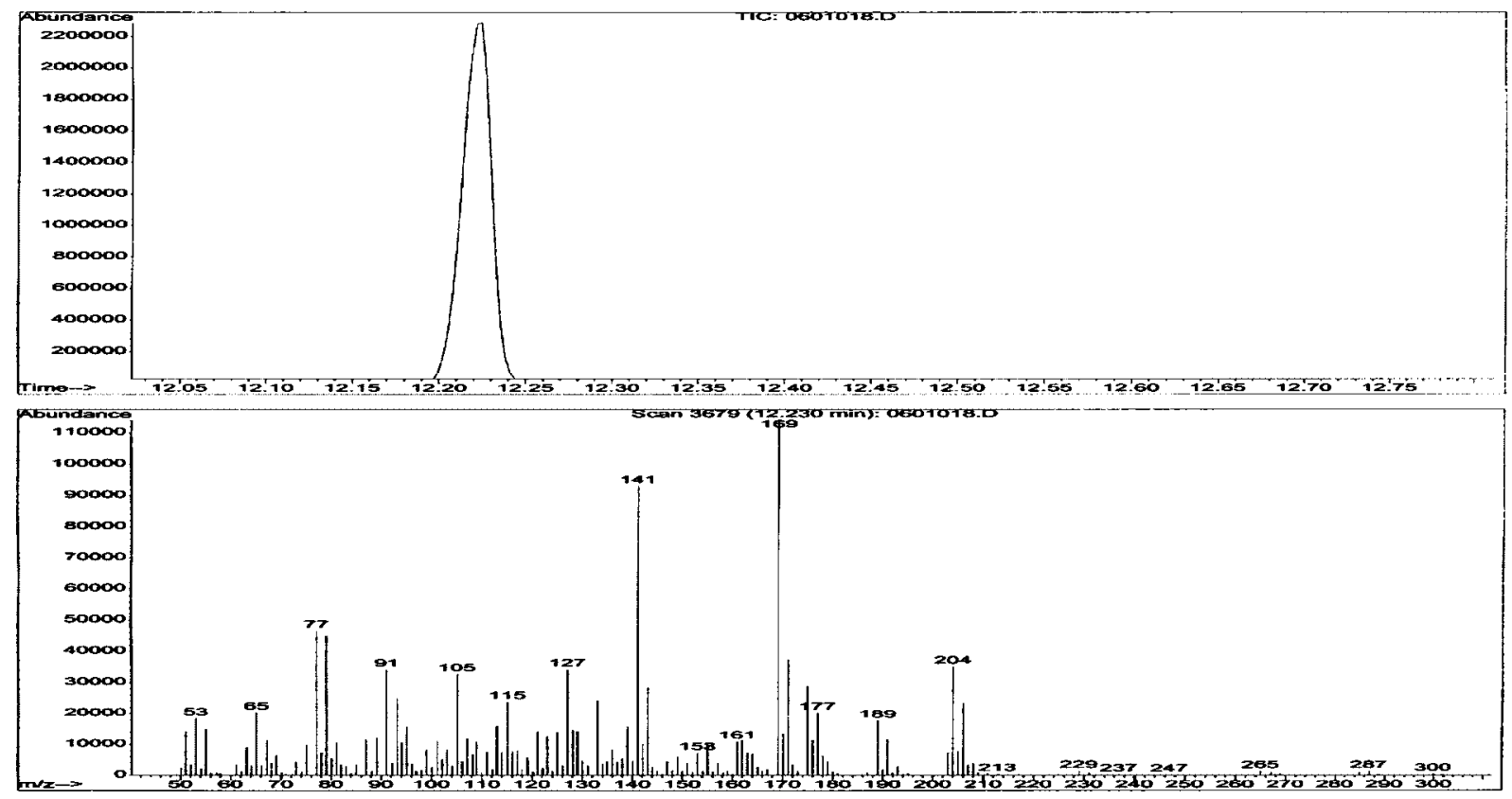

Fig. 4. GC-MS of double adduct $16 . \mathrm{M}^{+}=300, \mathrm{M}^{+}-\left(\mathrm{CH}_{2}-\mathrm{CCl}_{2}\right)=204, \mathrm{M}^{+}-\left(\mathrm{CH}_{2}-\mathrm{CCl}_{2}\right), \mathrm{Cl}=169(100 \%), \mathrm{M}^{+}-\mathrm{Cl}_{-}-\mathrm{CCl}_{2}-$ $\mathrm{CH}_{3}-\mathrm{C}_{2} \mathrm{H}_{2}=141$.

methylbicyclo[4.1.0]heptane (16), obtained with total yield of $41 \%$ from $\underline{4}$, displayed 1.95 and 2.18 ppm signals corresponding to $\mathrm{H} 2$ and to the methylene at $\mathrm{H} 8$, the characteristic protonated cyclopropane carbon in C-13 NMR resonated at 25.2, $\underline{\mathrm{C}} 2$ and 20.4, $\underline{\mathrm{C}} 8 \mathrm{ppm}$ and the GC-MS spectrum confirm the structure (Fig. 4).

Molecular modelling of $\underline{16}$ of the two isomeric structures showed lower energy for cis isomer $\underline{16}$ (17 kcal/mol, Fig. 7). From the GC-MS this ratio (cis/trans) was evaluated $95: 5$, the 16 cis had a shorter retention time.

The two other dihalocyclopropane derivatives $\underline{17}$ and $\underline{18}$, obtained in $3: 1$ ratio, respectively (total yield of $47 \%$ ), displayed cyclopropane only on the endocyclic double bond and only on the methylene double bond of the other. The NMR characteristic features witnessing their differences are in particular proton and carbon signals of two double bond systems with two olefinic methylene protons and one cyclopropane methylene in the spectrum of $\underline{18}$ and one proton on the endocyclic double bond $(\mathrm{H} 2$ at $5.39 \mathrm{ppm}$ ) and methelyne cyclopropane proton at $1.95 \mathrm{ppm}$ for H8 and the GC-MS spectrum confirm the structures (Fig. 5a, b and c). The tetrachloro limonene derivative 16 produced under the Hiyama $\mathrm{Cr}^{+2}$ in situ reagent, yielded 5\% of allene-aldehyde mixture products, while the mixture dichloro derivatives $\underline{17}$ and $\underline{18}(3: 1)$ gave a small yield of allene-aldehyde mixture at ca $1 \%$. These compounds were identified by proton and carbon-13 NMR, and confirmed by mass spectrometry.

The allene-aldehyde $\underline{19}$ was observed in both rearrangements of $\underline{16}$ with $\mathrm{Cr}^{+2}$ produced in situ and with commercial $\mathrm{Cr}^{+2}$, but the dihalocyclopropane unsaturated aldehyde $\underline{20}$ was observed only with $\mathrm{Cr}^{+2}$ produced in situ (Scheme 4).

Of the two possible orientations of the dichlorocyclopropane moiety of 17 toward the $\alpha$-isopropenyl group of the natural $\underline{4}$, the most stable is that whose isoprenyl is oriented trans (dichlorocyclopropane $\underline{17}$ trans). Molecular modelling of the two isomeric structures showed lower energy for trans isomer 17 $(9.3 \mathrm{kcal} / \mathrm{mol}$, Figs 8 and 9$)$. 


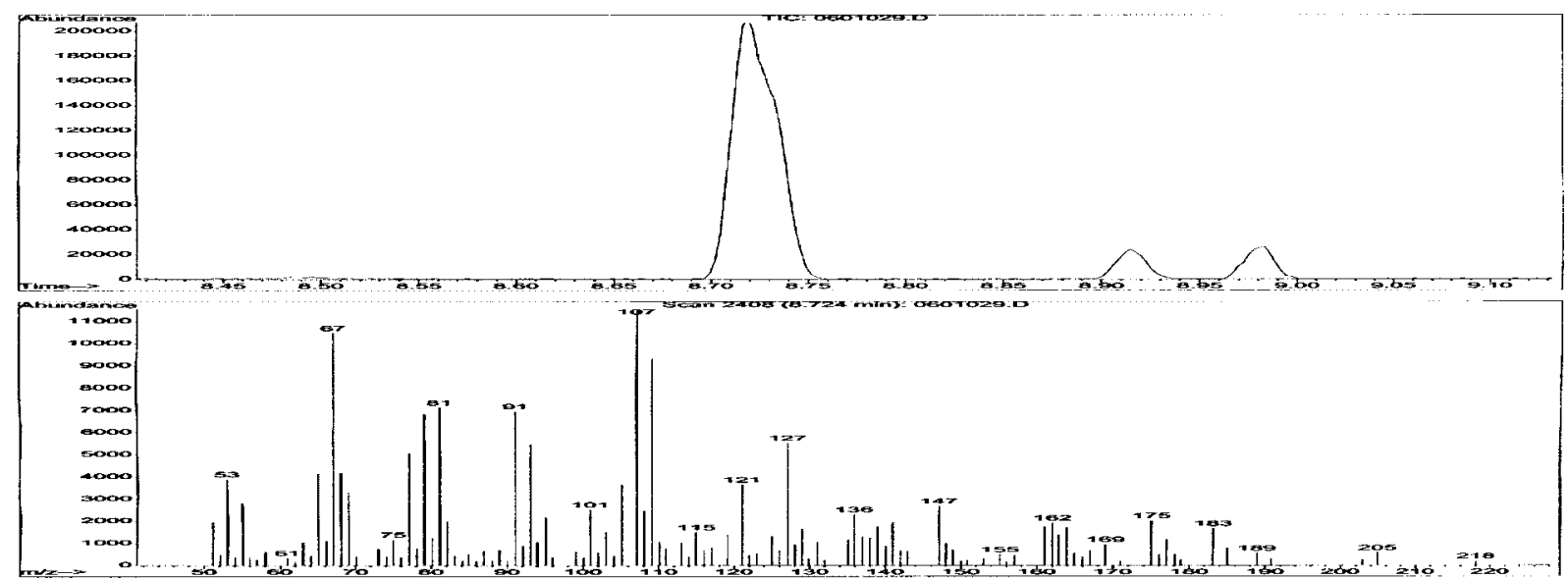

(a)

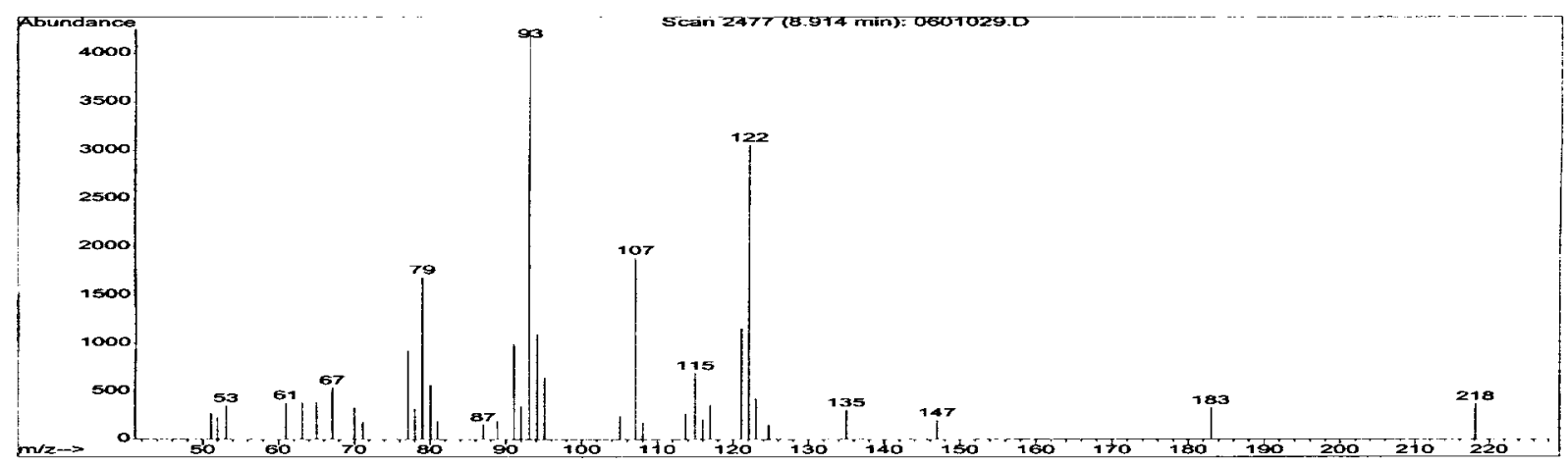

(b)

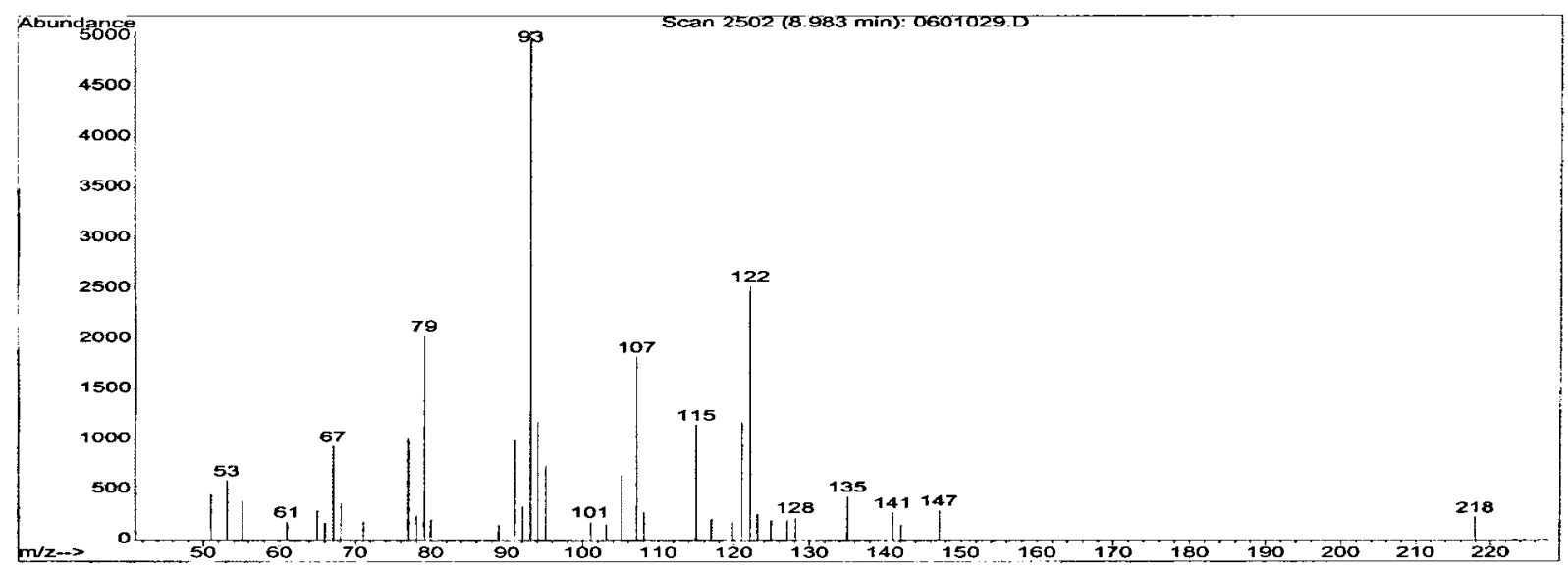

(c)

Fig. 5. (a) GC-MS of the mixture 17 and $\underline{18}$. For $\underline{17}, \mathrm{M}^{+}=218, \mathrm{M}^{+}-\mathrm{Cl}=183, \mathrm{M}^{+}-\mathrm{CH}_{3}-\mathrm{CCl}_{2}=121,\left(M^{+}-\mathrm{CH}_{2}-\right.$ $\left.\mathrm{C}-\mathrm{CCl}_{2}\right)-2 \mathrm{H}=107(100 \%)$. (b) GC-MS of $\underline{18}, \mathrm{M}^{+}=218, \mathrm{M}^{+}-\mathrm{Cl}=183, \mathrm{M}^{+}-\mathrm{CH}_{2}-\mathrm{CCl}_{2}=122, \mathrm{M}^{+}-\mathrm{CH}_{2}-\mathrm{CCl}_{2}-\mathrm{H}_{2}=93$ (100\%). (c) GC-MS of isomer of $\underline{18}, \mathrm{M}^{+}=218, \mathrm{M}^{+}-\mathrm{CH}_{2}-\mathrm{CCl}_{2}=122, \mathrm{M}^{+}-\mathrm{CH}_{2}-\mathrm{CCl}_{2}-\mathrm{H}_{2}=93(100 \%)$. 

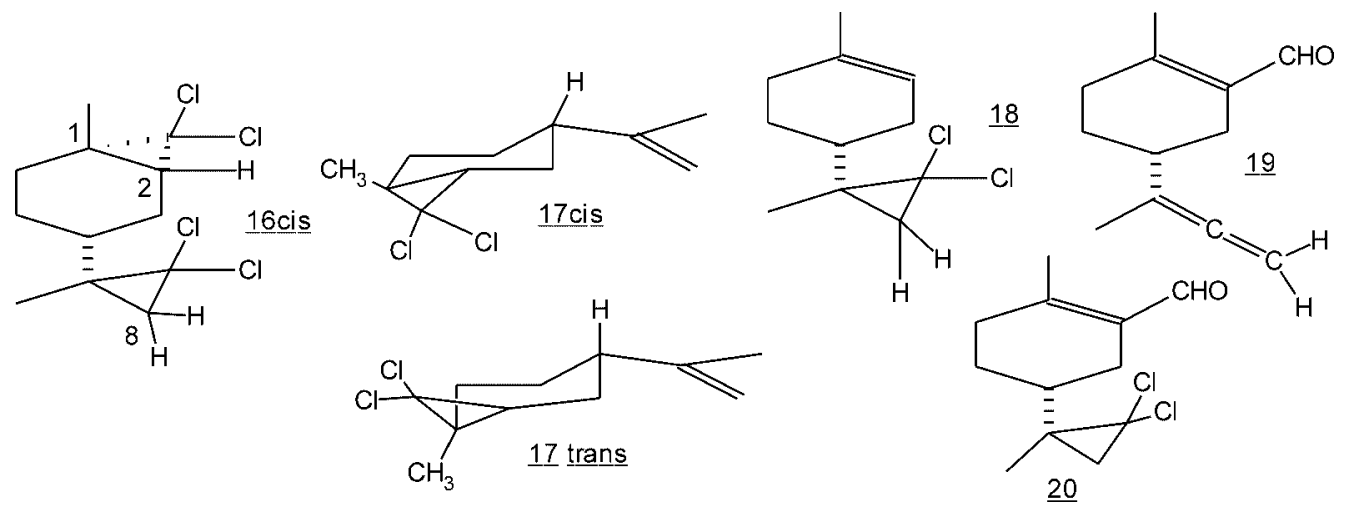

Scheme 4. Limonene $\underline{4}$ dichlorocyclopropane adducts $\underline{16}-\underline{18}$ and rearrangement products $\underline{19}$ and $\underline{20}$.

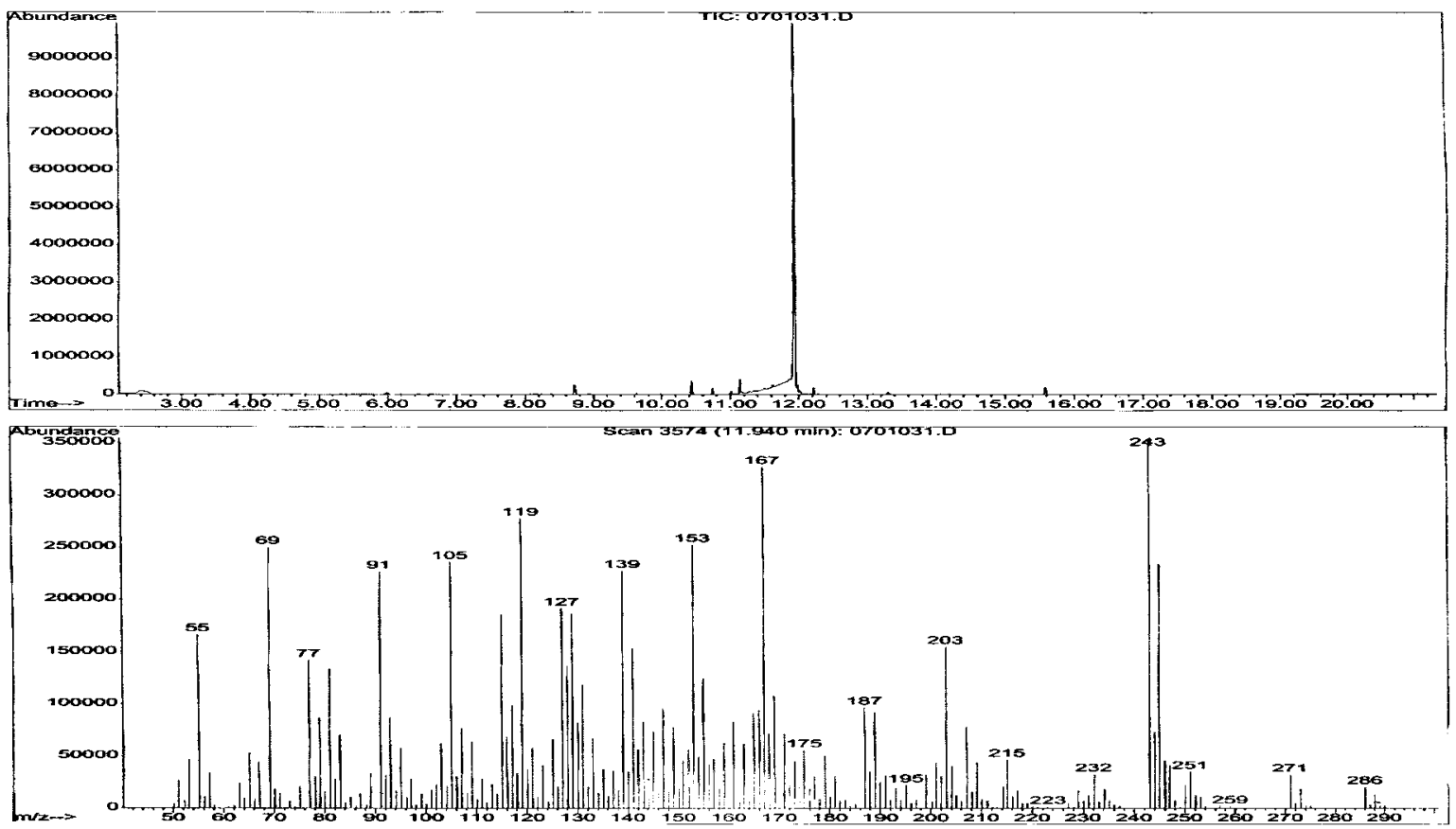

Fig. 6. GC-MS of cubebene adduct $21 . \mathrm{M}^{+}=286, \mathrm{M}^{+}+2=288(2 \mathrm{Cl}), \mathrm{M}^{+}{ }_{-1 \mathrm{Pr}}=243,245(2 \mathrm{Cl})(100 \%), \mathrm{M}^{+}-\mathrm{Cl}=251$, $253(2 \mathrm{Cl}), \mathrm{M}^{+}-\left(\mathrm{Cl}-\mathrm{C}_{6} \mathrm{H}_{12}\right)=167,169(1 \mathrm{Cl})$.

The rearrangement on mixture of $\underline{17}$ and $\underline{18}$, was also being tested, according to Hiyama $\mathrm{Cr}^{+2}$ in situ formation condition. The compound $\underline{17}$ rearranges to aldehyde, and the isomer $\underline{18}$ produces monochloro allenic product in $3 \%$ of total yield. Commercial $\mathrm{Cr}^{+2}$ does not lead to any considerable rearrangement results.

Finally, we tested the dihalocyclopropanation of cubebene ( $\underline{5})$ and observed the formation of the dichlorocyclopropane derivative (21) in the $\alpha$-position (Scheme 5). The NMR spectrum shows that the proton of double bond in $\underline{5}$ at $5.00 \mathrm{ppm}$, is shifted to $2.31 \mathrm{ppm}$ which confirms the formation of a second cyclopropane ring. The GC-MS spectra showed a molecular ion at $m / z=286$ corresponding to dihalocyclopropane cubebene (21), with the characteristic isotopic two chlorine pattern (Fig. 6). Three C-13 


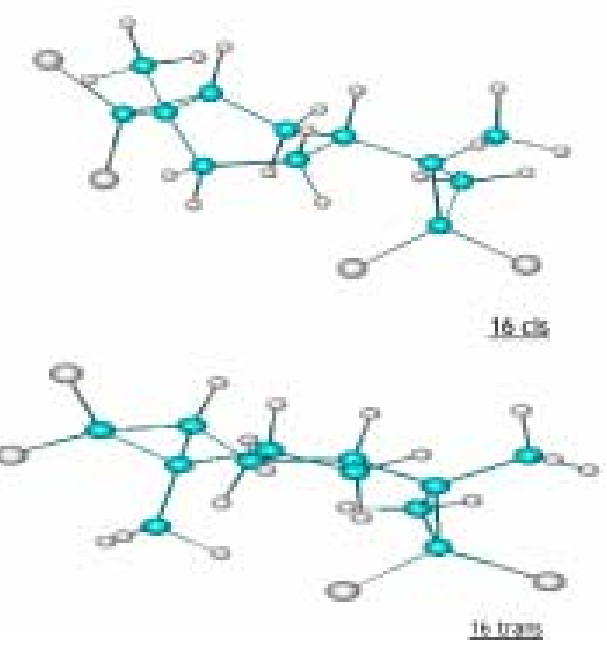

Fig. 7. Molecular modelling of $\underline{16}$ cis and trans.

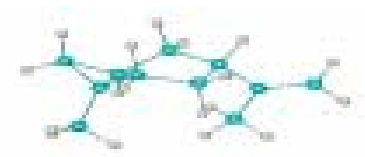

Fig. 8. Molecular modelling of $\underline{17}$ trans.

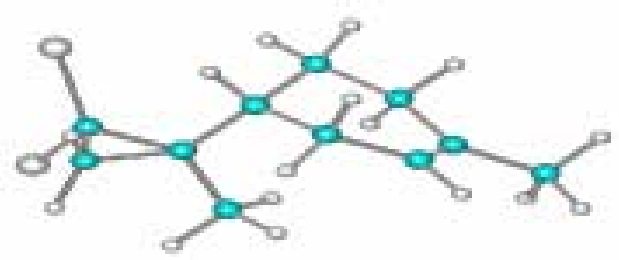

Fig. 9. Molecular modelling of $\underline{18}$.

signals provide at 46.6 at 37.4 and 67.5 respectively, are additional confirmation of the structure, assigned to $\mathrm{C} 1, \mathrm{C} 2$ and C16. Despite the successful transformation of cubebene (5) into the dihalocyclopropane derivative $\underline{21}$ (with $87 \%$ of total yield from proton NMR spectrum), the tentative rearrangement of this highly crowded molecule failed (Fig. 10). 


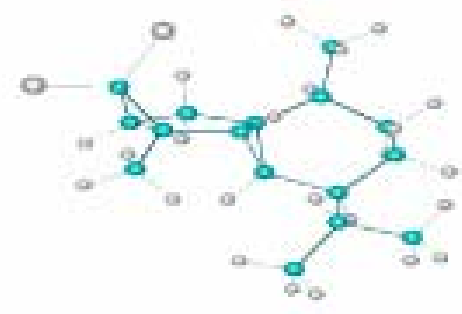

Fig. 10. Molecular modelling of cubebene adduct $\underline{21}$.
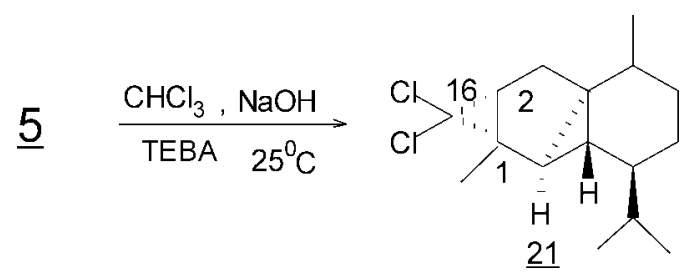

Scheme 5. Cubebene ( $\underline{5}$ ) dichlorocyclopropane adduct.

\section{Conclusion}

This preliminary report on the rearrangement of dihalocyclopropane derivatives of several compounds promoted by Hiyama $\mathrm{Cr}^{+2} / \mathrm{Cr}^{+3}$ system confirmed the formation of new dihalomethylvinyl intermediate product further hydrolyzed to the $\alpha, \beta$-unsaturated aldehyde and acid. Although, the yield of this reaction is small and the total yield of transformation of starting material does not exceed $40 \%$, this reaction is apparently new. In particular, the difference between this reaction and the Makosza extended dihalocarbocyclic compound is striking. The relative efficiency of the synthese of $\alpha, \beta$-unsaturated aldehyde with $\mathrm{Cr}^{+2}$ created in situ and $\alpha, \beta$-unsaturated acid with commercial $\mathrm{Cr}^{+2}$, could be related to the purity of the reagent and a higher ratio of $\mathrm{Cr}^{+2} / \mathrm{Cr}^{+3}$ generated by the in situ route.

The major dihalomethylvinyl product, $\underline{9}$ or $\underline{22}$ were observed with a maximum of $15 \%$ for both dihalocyclopropanes $\underline{6}$ and $\underline{7}$. The simultaneous presence of $\mathrm{Cr}^{+2} / \mathrm{Cr}^{+3}$ resulting from the reduction of $\mathrm{Cr}^{+3} / \mathrm{H}^{-}$seems to be necessary to obtain this rearrangement.

The rearrangement of some dihalocyclopropane derivatives of natural product could be a simple way to introduce aldehyde or acid functions on to these molecules.

More were is in progress in order to specify the influence of the neighboring group of varying different electronic effects on the direction of this rearrangement, in particular, the effect of electron-withdrawing groups placed near the dihalocyclopropane substrate site.

\section{Experimental}

All products were bought from Aldrich Chemicals. The NMR spectra were recorded on Brucker $200 \mathrm{MHz}$, in $\mathrm{CDCl}_{3}$. Chemical shifts were reported in $\delta(\mathrm{ppm})$ with TMS as internal reference. The GC-MS spectra were recorded on the Nermag Riber 30-10 GC-MS system with BP1 capillary column $(25 \mathrm{~m}, \varnothing 0.3 \mu \mathrm{m})$ and Agilent 6890 series, column HP-5MS (5\% phenyl-methylpolysiloxane) $30 \mathrm{~cm}, \varnothing$ $0.25 \mu \mathrm{m}$. 


\subsection{General procedure of synthesis of dihalocyclopropane}

In $500 \mathrm{ml}$ round-bottomed flask, a $\mathrm{NaOH} 50 \%$ solution ( $15 \mathrm{~g}$ of hydroxide $/ 15 \mathrm{ml}$ of water) was prepared (ice bath), $25 \mathrm{ml}$ of chloroform with $1 \mathrm{~g}$ of catalyst tributylammonium chloride (TEBA) were added to the $\mathrm{NaOH}$ solution, finally $10 \mathrm{ml}$ of the substrate $\underline{1}$ (same volume for $\underline{2}, \underline{3}$ and $\underline{4}$ ) except $\underline{5}$ was added, and the mixture was stirred for $2 \mathrm{~h},(24 \mathrm{~h}$ for $\underline{4}$ and $\underline{5})$ at room temperature. The reaction was controlled with TLC, then after the addition of water extracted with $\mathrm{CH}_{2} \mathrm{Cl}_{2}$ and the products were purified via the chromatography column on silica gel (basic alumina for 4 ).

\subsection{General procedure of the rearrangement with $\mathrm{Cr}^{+2}$ in situ}

A solution of $0.5 \mathrm{~g}$ of chromium chloride (III) and $0.6 \mathrm{~g}$ of $\mathrm{LiAlH}_{4}$ with $5 \mathrm{ml}$ of THF were mixed in a $50 \mathrm{ml}$ round-bottomed flask, and stirred for 30 minutes. The changing color from violet to green indicated the formation of $\mathrm{Cr}^{+2}$. The solvent was replaced with $8 \mathrm{ml}$ of DMF and $0.1 \mathrm{~g}$ of the dihalocyclopropane adduct were added at room temperature. The mixture was stirred for $24 \mathrm{~h}$. After the hydrolytic workup (10 $\mathrm{ml}$ of water and $10 \mathrm{ml}$ of hexane-ether $(1: 1)$ mixture) the sample analyzed via the GC-MS.

\subsection{General procedure of the rearrangement with $\mathrm{Cr}^{+2}$ (commercial)}

A solution of 0.5 of chromium chloride (II) and $0.1 \mathrm{~g}$ of the dihalocyclopropane adduct with $8 \mathrm{ml}$ of DMF were mixed, in a $50 \mathrm{ml}$ round-bottomed flask, and stirred for $24 \mathrm{~h}$ at room temperature. After the usual workup (10 $\mathrm{ml}$ of water and $10 \mathrm{ml}$ of hexane-ether $(1: 1)$ mixture) the sample was analyzed via the GC-MS.

Molecular modeling calculations were done with help of Hyperchem ${ }^{\mathrm{TM}} 6.03$ (@2000 Hypercube, Inc.). All spectral material (H-1, C-13, 1D, 2D NMR, GC-MS, EI and CI) for compounds of this paper are available on request from the corresponding author (C.K. Jankowski) at the e-mail address of the Université de Moncton.

\section{Acknowledgements}

We would like to express our gratitude to Mr. M. Ferron (U de Moncton) for recording of some of our GC-MS spectra. This work was supported by the FESR (U de M) research grant.

\section{References}

[1] M. Makosza and M. Wawrzynkiewicz, Tetrahedron Lett. (1969), 4659.

[2] W.V. Doering and A.K. Hoffmann, J. Am. Chem. Soc. 76 (1954), 6162.

[3] S. Landor, Chemistry of Allenes, Vol. 1, Academic Press, New York, 1982, p. 2.

[4] C.K. Jankowski, G. LeClair, M.-R. van Calsteren, J.M.R. Bélanger and J.R.J. Paré, Can. J. Chem. 79 (2001), 1906.

[5] E. Diaz, C.K. Jankowski, A. Ortega, C. Guerrero, A. Guzman, B.E. Lizama and A.F. Benitez, Nat. Prod. Lett. 12 (1998), 241.

[6] T. Hiyama, Y. Okude, I.K. Kumura and H. Nozaki, Bull. Chem. Soc. Japan 55 (1982), 561

[7] K. Reimer and F. Teimann, Ber. 9 (1876), 824, 1268, 1285.

[8] W.V. Doering, J. Am. Chem. Soc. 76 (1954), 6162; P.M. LaFlamme, Tetrahedron. 2 (1958), 75.

[9] G. Ciamician and N. Dennstedt, Ber. 14 (1881), 1153.

[10] G.W. Griffin, J. Covell, R.C. Petterson, R.M. Dodson and G. Klose, J. Am. Chem. Soc. 87 (1965), 1410.

[11] C.H. Heathcock, Tetrahedron Lett. 34 (1978), 1185.

[12] B. Wang and C. Deng, Tetrahedron Lett. 44 (1988), 7355. 


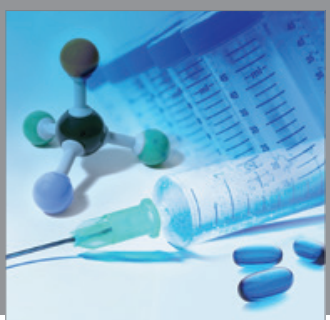

International Journal of

Medicinal Chemistry

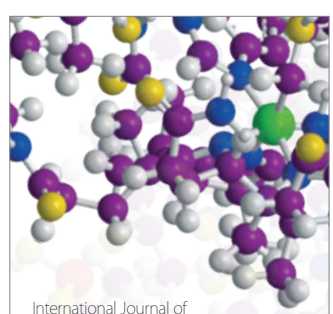

Carbohydrate Chemistry

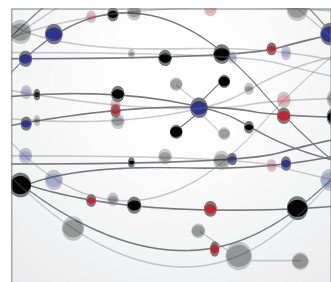

The Scientific World Journal
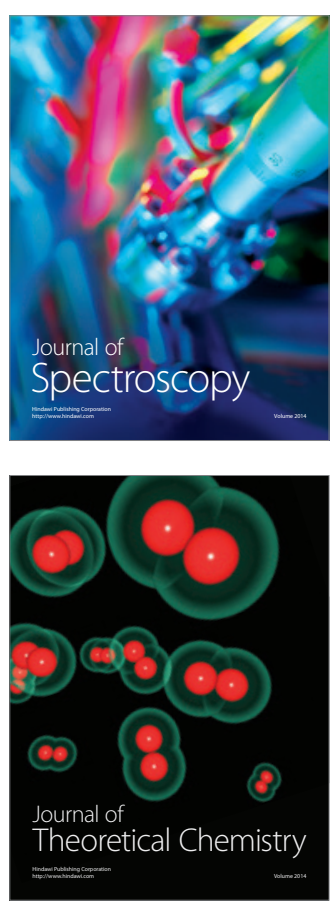
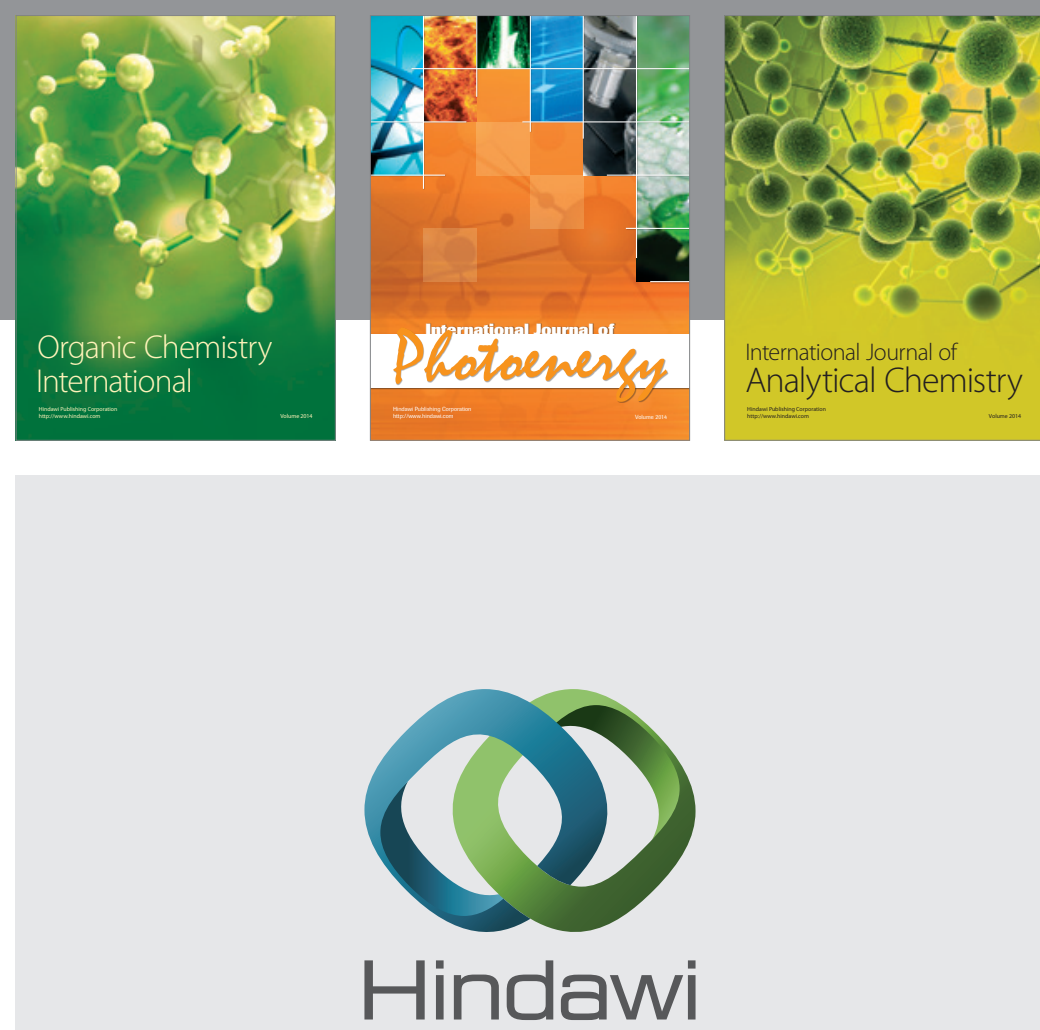

Submit your manuscripts at

http://www.hindawi.com
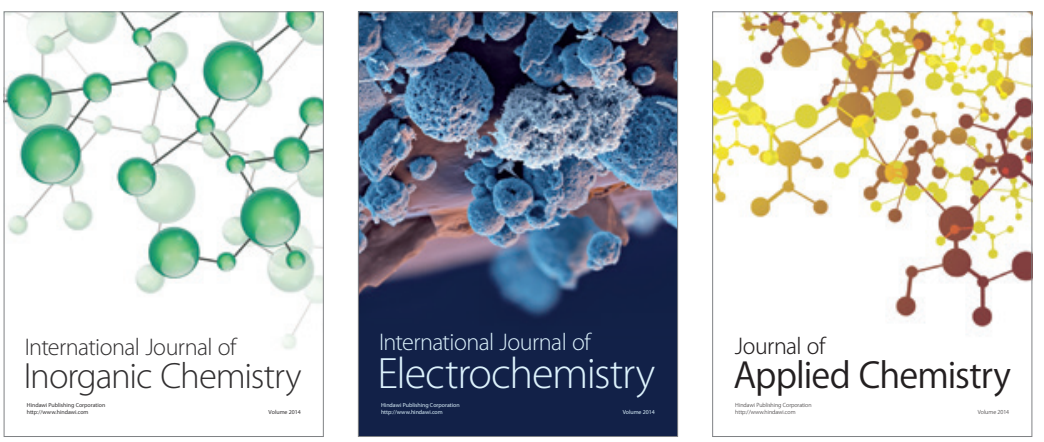

Journal of

Applied Chemistry
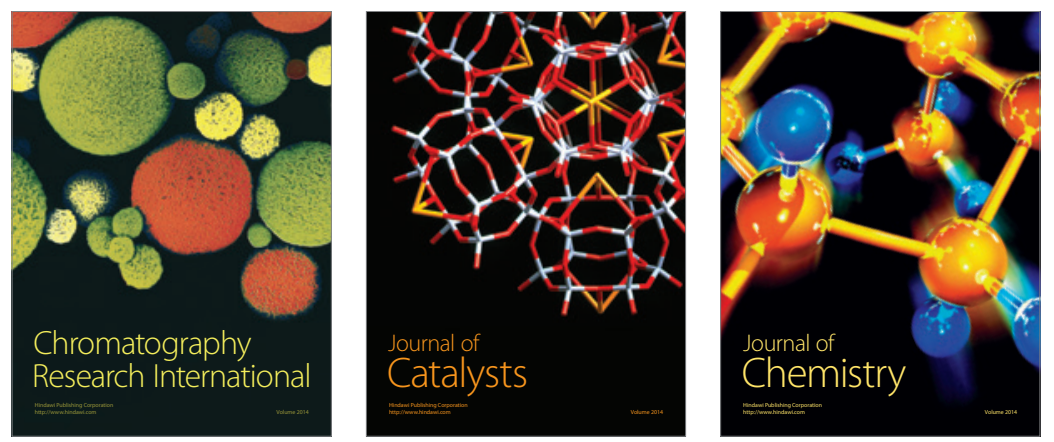
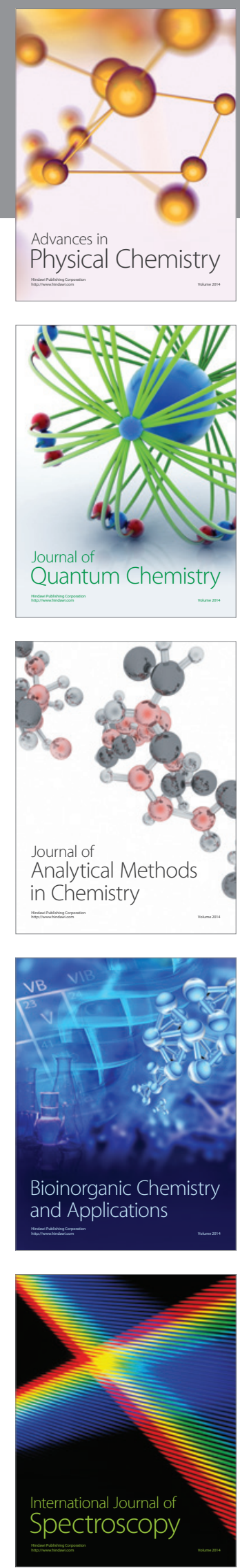